\title{
Guest editorial Rethinking non-financial reporting in Europe: challenges and opportunities in revising Directive 2014/95/EU
}

\section{Background}

Recent years have seen the wide adoption of non-financial reports by firms. The disclosure of non-financial information has come in response to pressures from stakeholders regarding firms' contributions to sustainable development (Mio et al., 2020; Pizzi et al., 2021). In this sense, non-financial reporting practices have evolved from activities conducted by socially responsible enterprises to activities conducted to comply with the external pressures of stakeholders, such as regulators, investors and citizens (Lehner and Harrer, 2019; Venturelli et al., 2021). Also, further stimulus was provided by the 2030 Agenda, which requires the Member States to introduce new forms of regulation within their jurisdictions to increase the transparency of financial markets (United Nations, 2015).

Directive 2014/95/EU represents the main initiative developed in Europe to contribute to the 2030 Agenda actively. The Directive was introduced in response to the external pressures from investors regarding the exigence to provide more information about the social and environmental impacts of European public interest entities (PIEs) (Venturelli et al., 2020). However, the first years after the launch of Directive 2014/95/EU have seen scepticism from policymakers and academics.

From an academic perspective, during the last years, accounting scholars underlined the need to rethink Directive 2014/95/EU. Several studies show limited effects from the transposition of Directive 2014/95/EU on non-financial reporting's transparency, assurance practices, data comparability and business models (Doni et al., 2019; Nicolo et al., 2020; Di Tullio et al., 2019; Venturelli and Pizzi, 2020). Additionally, preliminary studies conducted before the transposition of the rule by the Member States suggested criticisms related to the definition of Directive 2014/95/EU's boundaries (Luque-Vílchez and Larrinaga, 2016; Monciardini, 2016; La Torre et al., 2018).

Regarding the policymakers' response, the European Commission included the revision of Directive 2014/95/EU within its agenda. Specifically, revisions were judged necessary to fill some gaps identified over the years. The main criticisms the European Commission (2020a, b) reports in the Directive 2014/95/EU impact assessment are as follows:

(1) There is inadequate publicly available information about how non-financial issues, and sustainability issues in particular, impact companies, and about how companies themselves impact society and the environment. In particular,

- Reported non-financial information is not sufficiently comparable or reliable.

- Companies do not report all non-financial information that users think is necessary, and many report information that users do not find relevant.

- Some companies from which investors and other users want non-financial information do not report such information.

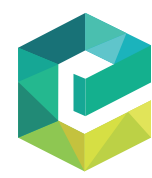

Journal of Applied Accounting Research Vol. 23 No. 1, 2022 DOI 10.1108/JAAR-02-2022-265 
JAAR

23,1

2
- It is hard for investors and other users to find non-financial information even when it is reported.

(2) Companies incur unnecessary and avoidable costs related to reporting non-financial information. Companies face uncertainty and complexity when deciding what nonfinancial information to report, and how and where to report such information. In the case of some financial sector companies, this complexity may also arise from different disclosure requirements contained in different pieces of European Union (EU) legislation. Companies are under pressure to respond to additional demands for nonfinancial information from sustainability rating agencies, data providers and civil society, irrespective of the information that they publish as a result of the NFRD.

However, similar to the first debates about the implementation of Directive 2014/95/EU (Monciardini, 2016), the opinions collected during the public consultations reveal different stakeholder approaches toward non-financial reporting practices (European Commission, 2020b). In particular, one of the main insights is the exigence to revise Directive 2014/95/EU to fill gaps related to lack of comparability (71\% of respondents), reliability $(60 \%)$ and relevance $(57 \%)$. Other criticisms are related to the materiality assessment's transparency $(71 \%)$, the need to identify new tools to support the development of digital reports $(64 \%)$ and the necessity to identify a common reporting standard ( $82 \%)$.

\section{The special issue}

The revision of Directive 2014/95/EU will represent a new challenge for accounting. The theoretical contribution of accounting scholars could help to identify the main strengths and weaknesses over the first six years following the introduction of Directive 2014/95/EU. As observed by Bebbington (2013), accounting scholars play a central role in society due to their evidence-based perspective.

In the light of these pieces of evidence, this special issue aims to contribute to the academic and practitioner debates on mandatory non-financial reporting in Europe through an accounting lens. In detail, the following 13 articles have been selected.

\section{Double materiality and the shift from non-financial to European sustainability reporting: review, outlook and implications}

Baumüller and Sopp (2022) outline the development of the principle of materiality in the European accounting framework from the Modernization Directive (2003/51/EC) to the NFI Directive (2014/95/EU) and on to the proposals for a Corporate Sustainability Reporting (CSR) Directive (2021/0104 (COD)). The authors highlight how the requirements for corporate reporting in terms of sustainability matters have changed, underlining the main issues that require further attention by practitioners, researchers and legislators. Using a historical methodological approach, the authors outline a shift in rationales and political priorities as well as in implications for European companies that need to fulfil the reporting requirements.

\section{Financial analysts' reaction to voluntary integrated reporting: cross-sectional} variation in institutional enforcement contexts

Drawing on voluntary disclosure theory, Rossignoli et al. (2022) conducted a quantitative empirical research study to explore the moderating role of country-level institutional characteristics on the associations between voluntary IR release and analyst forecast accuracy and dispersion. The study demonstrates that financial analysts rely on IR to predict earnings per share, in particular, where the institutional enforcement is strong. In these contexts, the accuracy of analysts' forecasts for IR adopters is better than it is for non-IR adopters. This conclusion assumes greater significance in the future European scenario 
where - because of the revised Directive to be issued soon - an improvement in the institutional enforcement is expected. Therefore, this improvement is likely to have positive effects not only on the determinants of the disclosure of sustainability but also on its effect for the capital market by enhancing the predictive capabilities of financial analysts in forecasting IR adopters' performance.

\section{From voluntarism to regulation: effects of Directive 2014/95/EU on} sustainability reporting in the EU

Following the theoretical approach proposed by Ioannou and Serafeim (2012), Ottenstein et al. (2022) conducted an interesting quantitative analysis about a large sample of European PIEs interested by the effects of the Directive 2014/95/EU. Using a matched sample of European firms exceeding the relevant size thresholds for the Directive 2014/95/EU, the results show that the Directive has improved both quantitative and qualitative characteristics of sustainability reporting by European PIEs. The analyses provide support that the Directive has generally met its objectives of improving transparency by increasing the information provided on the five thematic aspects (i.e. reporting quantity) and the goal of increasing the credibility of non-financial information provided by large PIEs. However, the analysis confirms that the Directive does not impact on the comparability of sustainability reporting in the EU.

\section{How cultural dimensions are shaping social expectations: the case of European state-owned enterprises' nonfinancial reporting}

Zanellato and Tiron-Tudor (2022) conducted an original analysis about European stateowned enterprises (SOEs) interested by the effects of the Directive 2014/95/EU. The paper adopts a mixed approach. First, it employs the content analysis to investigate the disclosure level on 22 of the 24 European SOEs. Second, the authors demonstrate how cultural dimensions take a different role when a change in regulation is introduced using the qualitative comparative analysis (QCA). The results reveal a slight increase in disclosure from the year before introducing the Directive. Additionally, the results demonstrate how none of Hofstede's cultural dimensions is responsible for high disclosure levels, though the sufficiency analysis outlines several combinations of different cultural dimensions that lead to high disclosure levels.

\section{Integrated reporting quality and cost of debt financing}

Raimo et al. (2022) evaluated the signalling effects related to the disclosure of non-financial information. Building on a sample of 536 companies, the authors found the existence of a positive relationship between cost of debt and the quality of the non-financial information disclosed by integrated reports' adopters. Results show the goodness of IR as an ideal solution to fulfil the obligations imposed by Directive 2014/95/EU.

\footnotetext{
Non-financial key performance indicators: what determines the differences in the quality and quantity of the disclosures?

Building on a sample of PIEs operating in Poland after the introduction of the Directive 2014/ 95/EU, Zarzycka and Krasodomska (2022) developed an interesting and original paper about the quality and quantity of the disclosed non-financial key performance indicators (KPIs). The study findings indicate that the sample companies provide a variety of non-financial KPIs in a manner that makes their effective comparison difficult.
} 
JAAR

23,1

4

Performance and (non) mandatory disclosure: the moderating role of the Directive 2014/95/EU

Cupertino et al. (2022) shed light on how Directive 2014/95/EU affects financial performance as well as its moderation effect on the relationship between financial and non-financial performance. The authors argued that non-financial regulation negatively affects firms' operating profitability and shareholder value while produces no effects on debtholders' returns. Nevertheless, the Directive 2014/95/EU has general positive moderating effects on the relationship between non-financial and financial performance, mitigating the direct costs induced by pursuing non-financial performance.

\section{Promoting sustainability assurance missions in the European directive regulatory context}

Gillet-Monjarret (2022) paid particular attention to sustainability assurance (SA). In particular, the author sheds light on the different strategies put in place by the providers appointed by regulations. Carrying out a discursive analysis of the promotion of SA on independent third-party body websites, the research highlights different strategies for promoting the implementation of assurance missions aimed at legitimizing their new skills. Nevertheless, it appears that the providers make very little reference to the quality of nonfinancial information as the objective of SA missions.

\section{Revising non-financial reporting directive and role of board of directors: a lost opportunity?}

Cosma et al. (2022) provided evidence of the relationship between individual directors' tasks and behaviours, non-financial reporting and Sustainable Development Goals (SDGs). Adopting a methodological approach based on survey research, the authors developed an empirical using an ordered probit model. The results show that a greater involvement of a board member in the non-financial reporting process is associated with a stronger commitment towards sustainable development. Specifically, the involvement in materiality assessment is positively associated with more proactive behaviours towards sustainability.

\section{Sustainable corporate governance and non-financial disclosure in Europe: does} the gender diversity matter?

Nicolò et al. (2022) analysed the enabling role covered by corporate governance on mandatory nonfinancial reporting. In detail, the research contributes to the literature by disentangling the links between gender diversity and ESG disclosure over a period that covers a long season of European regulations and measures that affected both non-financial reporting practices and the board of directors' composition. Findings allow to spotlight the positive role exerted by the presence of women directors on the boards in enhancing ESG disclosure, both at the overall and specific (individual ESG scores) level.

The climate-related information in the changing EU directive on non-financial reporting and disclosure: first evidence by Italian large companies

Lombardi et al. (2022) investigated the quality and quantity of climate-related information disclosed by PIEs in the non-financial disclosure scenario. The research contributes to extending the existing literature, drafting the state of the art of what is the quality and quantity of the climate-related information, which represents an emerging topic in social and environmental accounting. The results show the lack of several required climate-related information or a not in-depth presentation of information. Additionally, the findings enlarge 
previous theories on corporate disclosure, proposing new insights in the light of the recent interest in climate-related information.

\section{The multi-faceted dimensions for the disclosure quality of non-financial information in revising directive 2014/95/EU}

Fiandrino et al. (2022) summarized the scientific debate on non-financial information using an integrative literature review that assesses and synthesizes the scientific knowledge and the annexed documents collected during the public consultation for the review of NFRD. Findings show that there is a common consensus between scientific literature and the annexed documents of the consultation process on the review of the NFRD on the need to enhance a double-materiality perspective, to provide specific contents on sustainability issues, to clarify the relevance of NFI and to embed NFI into the management report in an integrated manner. Furthermore, there is an alignment related to timeliness in favour of a risk management procedure and a forward-looking approach.

\section{The non-financial reporting practices of Hungarian listed public interest entities considering the 2014/95/EU directive}

Lippai-Makra et al. (2022) evaluated the effects of the Directive 2014/95/EU in Hungaria. Adopting a theoretical framework used in previous studies about non-financial reporting in Europe, the authors collected interesting insights about non-financial regulation in developing countries. Furthermore, the authors underlined the existence of a positive relationship between intangibles and the quality of the non-financial information disclosed by Hungarian companies.

\section{Concluding remarks}

This special issue aims to contribute to the scientific debate on Directive 2014/95/EU with new insights and evidence. As many events have radically impacted non-financial reporting in the last few months, this contribution is even more relevant. The current and perspective evolutionary pathway of sustainability accounting requires data, theories and insights to fully understand and interpret the first years after the transposition of the Directive 2014/95/ EU by the Member States.

The next years ahead will be characterized by new challenges for accounting scholars. The implementation of the IFRS sustainability standards, the development of new taxonomies and the introduction of new rules, standards and frameworks represent only few examples of the current and perspective environment. In this sense, we sincerely hope that our special issue will be useful to accounting scholars and will inspire new starting point for future research directions.

Andrea Venturelli

Dipartimento di Scienze dell'Economia, Universita del Salento, Lecce, Italy

Marco Fasan

Department of Management, Ca' Foscari University of Venice, Venice, Italy, and

Simone Pizzi

Dipartimento di Scienze dell'Economia, Universita del Salento, Lecce, Italy

\section{References}

Baumüller, J. and Sopp, K. (2022), "Double materiality and the shift from non-financial to European sustainability reporting: review, outlook and implications", Journal of Applied Accounting Research, Vol. 28 No. 5, pp. 863-887, doi: 10.1108/jaar-04-2021-0114. 
JAAR 23,1

Bebbington, J. (2013), “As a matter of policy”, Social and Environmental Accountability Journal, Vol. 33 No. 1, pp. 1-4.

Cosma, S., Leopizzi, R., Nobile, L. and Schwizer, P. (2022), "Revising the non-financial reporting directive and the role of board of directors: a lost opportunity?", Journal of Applied Accounting Research, Emerald Group Holdings, Vol. 23 No. 1, pp. 207-226, doi: 10.1108/JAAR-04-2021-0102.

Cupertino, S., Vitale, G. and Ruggiero, P. (2022), "Performance and (non) mandatory disclosure: the moderating role of the directive 2014/95/EU”, Journal of Applied Accounting Research, Vol. 23 No. 1, pp. 163-183, doi: 10.1108/JAAR-04-2021-0115.

Di Tullio, P., Valentinetti, D., Nielsen, C. and Rea, M.A. (2019), "In search of legitimacy: a semiotic analysis of business model disclosure practices", Meditari Accountancy Research, Emerald Group Publishing, Vol. 28 No. 5, pp. 863-887.

Doni, F., Bianchi Martini, S., Corvino, A. and Mazzoni, M. (2019), "Voluntary versus mandatory nonfinancial disclosure", Meditari Accountancy Research, Emerald Group Publishing, Vol. 28 No. 5, pp. 781-802.

European Commission (2020a), "Revision of the non-financial reporting directive", available at: https:// ec.europa.eu/info/law/better-regulation/have-your-say/initiatives/12129-Revision-of-NonFinancial-Reporting-Directive.

European Commission (2020b), "Consultation document - public consultation on the review of the nonfinancial reporting directive”, June, pp. 1-66.

Fiandrino, S., di Trana, M., Tonelli, A. and Lucchese, A. (2022), "The multi-faceted dimensions for the disclosure quality of non-financial information in revising directive 2014/95/EU", Journal of Applied Accounting Research, Emerald Group Holdings, Vol. 23 No. 1, pp. 274-300, doi: 10.1108/ JAAR-04-2021-0118.

Gillet-Monjarret, C. (2022), "Promoting sustainability assurance missions in the European Directive regulatory context", Journal of Applied Accounting Research, Vol. 23 No. 1, pp. 184-206, doi: 10. 1108/JAAR-04-2021-0085.

Ioannou, I. and Serafeim, G. (2012), "The consequences of mandatory corporate sustainability reporting”, SSRN Electronic Journal. doi: 10.2139/ssrn.1799589.

La Torre, M., Sabelfeld, S., Blomkvist, M., Tarquinio, L. and Dumay, J. (2018), "Harmonising nonfinancial reporting regulation in Europe: practical forces and projections for future research", Meditari Accountancy Research, Emerald Group Publishing, Vol. 26 No. 4, pp. 598-621.

Lehner, O.M. and Harrer, T. (2019), "Accounting for economic sustainability: environmental, social and governance perspectives", Journal of Applied Accounting Research, Vol. 20 No. 4, pp. 365-371.

Lippai-Makra, E., Kovács, Z.I. and Kiss, G.D. (2022), "The non-financial reporting practices of Hungarian listed public interest entities considering the 2014/95/EU directive", Journal of Applied Accounting Research, Vol. 23 No. 1, pp. 301-318.

Lombardi, R., Schimperna, F., Paoloni, P. and Galeotti, M. (2022), "The climate-related information in the changing EU directive on non-financial reporting and disclosure: first evidence by Italian large companies", Journal of Applied Accounting Research, Vol. 23 No. 1, pp. 250-273, doi: 10. 1108/JAAR-04-2021-0117.

Luque-Vílchez, M. and Larrinaga, C. (2016), "Reporting models do not translate well: failing to regulate CSR reporting in Spain”, Social and Environmental Accountability Journal, Taylor \& Francis, Vol. 36 No. 1, pp. 56-75.

Mio, C., Fasan, M., Marcon, C. and Panfilo, S. (2020), "The predictive ability of legitimacy and agency theory after the implementation of the EU directive on non-financial information", Corporate Social Responsibility and Environmental Management, April, pp. 1-12.

Monciardini, D. (2016), "The 'coalition of the unlikely' driving the EU regulatory process of nonfinancial reporting", Social and Environmental Accountability Journal, Routledge, Vol. 36 No. 1, pp. 76-89. 
Nicolo, G., Zanellato, G., Manes-Rossi, F. and Tiron-Tudor, A. (2020), "Corporate reporting metamorphosis: empirical findings from state-owned enterprises", Public Money and Management, Taylor \& Francis, pp. 1-10.

Nicolò, G., Zampone, G., Sannino, G. and De Iorio, S. (2022), "Sustainable corporate governance and non-financial disclosure in Europe: does the gender diversity matter?", Journal of Applied Accounting Research, Emerald Group Holdings, Vol. 23 No. 1, pp. 227-249, doi: 10.1108/JAAR04-2021-0100.

Ottenstein, P., Erben, S., Jost, S., Weuster, C.W. and Zülch, H. (2022), "From voluntarism to regulation: effects of directive 2014/95/EU on sustainability reporting in the EU", Journal of Applied Accounting Research, Vol. 23 No. 1, pp. 55-98, doi: 10.1108/JAAR-03-2021-0075.

Pizzi, S., Del Baldo, M., Caputo, F. and Venturelli, A. (2021), "Voluntary disclosure of Sustainable Development Goals in mandatory non-financial reports: the moderating role of cultural dimension”, Journal of International Financial Management and Accounting, John Wiley \& Sons, pp. 1-24.

Raimo, N., Caragnano, A., Mariani, M. and Vitolla, F. (2022), "Integrated reporting quality and cost of debt financing", Journal of Applied Accounting Research, Emerald Group Holdings, Vol. 23 No. 1, pp. 122-138, doi: 10.1108/JAAR-04-2021-0097.

Rossignoli, F., Stacchezzini, R. and Lai, A. (2022), "Financial analysts' reaction to voluntary integrated reporting: cross-sectional variation in institutional enforcement contexts", Journal of Applied Accounting Research, Emerald Group Holdings, Vol. 23 No. 1, pp. 29-54, doi: 10.1108/JAAR-042021-0112.

United Nations (2015), Transforming Our World: the Agenda 2030 for Sustainable Development.

Venturelli, A. and Pizzi, S. (2020), "What drives the level of non-financial assurance in PIEs? Empirical evidence on the European firms listed on Forbes 2000", in Del Baldo, M., Dillard, J., Baldarelli, M.-G. and Ciambotti, M. (Eds), Accounting, Accountability and Society, Springer International Publishing, pp. 245-265.

Venturelli, A., Pizzi, S., Caputo, F. and Principale, S. (2020), "The revision of nonfinancial reporting directive: a critical lens on the comparability principle", Business Strategy and the Environment. doi: 10.1002/bse.2598.

Venturelli, A., Principale, S., Ligorio, L. and Cosma, S. (2021), "Walking the talk in family firms. An empirical investigation of CSR communication and practices", Corporate Social Responsibility and Environmental Management, John Wiley and Sons, Vol. 28 No. 1, pp. 497-510.

Zanellato, G. and Tiron-Tudor, A. (2022), "How cultural dimensions are shaping social expectations: the case of European state-owned enterprises' nonfinancial reporting", Journal of Applied Accounting Research, Emerald Group Holdings, Vol. 23 No. 1, pp. 99-121, doi: 10.1108/JAAR-042021-0116.

Zarzycka, E. and Krasodomska, J. (2022), "Non-financial key performance indicators: what determines the differences in the quality and quantity of the disclosures?", Journal of Applied Accounting Research, Emerald Publishing, Vol. 23 No. 1, pp. 139-162, doi: 10.1108/JAAR-02-2021-0036. 